Received: November 26, 2017

Revision received: March 12, 2018

\title{
Design of Online Teaching Effect Test System of English Pronunciation Based on Web Database
}

\author{
Na Shen \\ Xinxiang Medical University
}

\begin{abstract}
The extensive use of the internet and information technology in the field of education, coupled with the diversification of distance learning, has resulted in the emergence of online test systems. According to the patterns and features of English pronunciation test, the key technologies of ASP.NET, Microsoft SQL Server 2005, and Windows Server 2003 are used to conduct the design of the online teaching effect test system of English pronunciation. Based on demand analysis and functional design, this paper mainly introduces the main function modules, key technology and function realization of the online teaching effect test system and devises a set of online examination system of English pronunciation based on Web technologies to facilitate the assessment of students' performance in the course of English pronunciation and intonation.
\end{abstract}

\section{Keywords}

English Pronunciation • Online Tests • Assisted Instruction • Web Database

\footnotetext{
${ }^{1}$ Correspondence to: Na Shen (MA), School of Foreign Languages, Xinxiang Medical University, Xinxiang 453003, China. Email:woshenna@126.com
} 
The rapid development of network technology, especially the extensive application of internet technology in the field of education, has brought new ideas to the development of colleges and universities. At the same time, it has also led to the emergence of a computerized online examination system (Han et al., 2015). The online examination system proposed in this paper provides online examination module, question bank management module and scoring module, three major modules (Zhang, 2017; James, Matthew \& Samrachana, 2018). The generation of questions, the submission of test papers, and the scoring of objective questions can be automatically completed online, all that the teachers need to do is maintaining the question bank (Freire \& Painho, 2014; Zacharis, 2015). At the same time, the system utilizes the development platform of Asp.NET and SQL Server 2005, adopts Windows Server technology for design and development, achieves simultaneous registration of multiple users, student login, online examination, score inquiry, password change, administrator management, question bank management, test paper scoring and other major modules (Ab, Cahyani \& Choo, 2017; Gupta \& Gupta, 2018; Ivanov \& Cyr, 2014). English is the second most widely used language in the world.English matters much for college students. The traditional examination method of English pronunciation is to conduct a test in the classroom according to a certain pattern, such as student number, so as to examine the student's learning situation (Lwoga, 2014; Schaffner, Schiefele, \& Ulferts, 2013). In order to better understand students' learning situation of English pronunciation and test the quality of teaching, our university began to consider using the computer technologies to develop a Web-based online examination system.

\section{System function design}

\section{Demand analysis}

This system mainly uses computers and the speech recognition software and networks to carry out the online examinations of English pronunciation and intonation, which embodies the teaching focus on the suprasegmental elements. The specific steps are as follows:

(1) Before the exam, multiple sets of questions for the corresponding exam subjects were created by relevant teachers to form an exam question bank (Gaudencio, Dantas \&Guerrero, 2014; Pimentel \& Nickerson, 2012)

(2) During the exam, after the students log on to the examination system, the system randomly selects questions from the exam question bank and automatically generates exam papers for students' according to a customized exam paper strategy.

(3) After the paper is submitted by the end of the exam, the system automatically marks the objective questions and gives a score;

(4) Students' pronunciation and intonation will be assessed with KayPENTAX and PRAAT (speech recognition software) and the system automatically calculates the students' total scores;

(5) Students can check their scores, the feedback and suggestions for further study afterwards (Ivanov \& Cyr, 2014; Lwoga, 2014). 
To achieve above contents, the system must have four major functional modules: student-teacher information management, online examination, paper-reading and scoring, and question bank management, as shown in Figure 1.

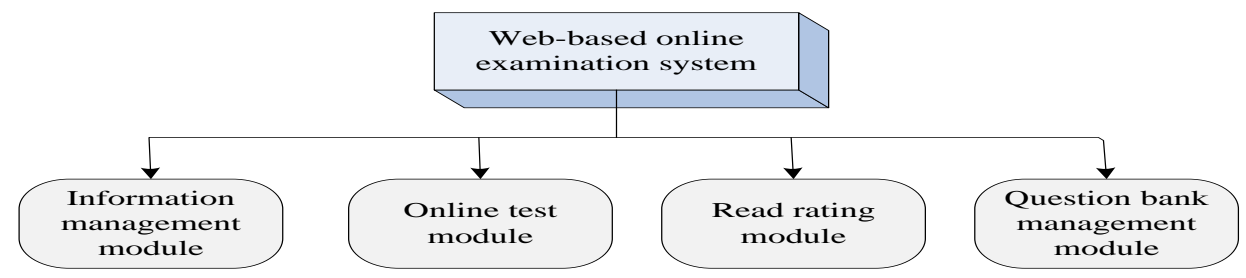

Figure 1. Online examination system function modules.

\section{Functional design}

The overall function of the system is devised basing on the 3 kinds of participants of the online examination system: students, teachers and administrators, the specific functional design is shown in Figure 2.

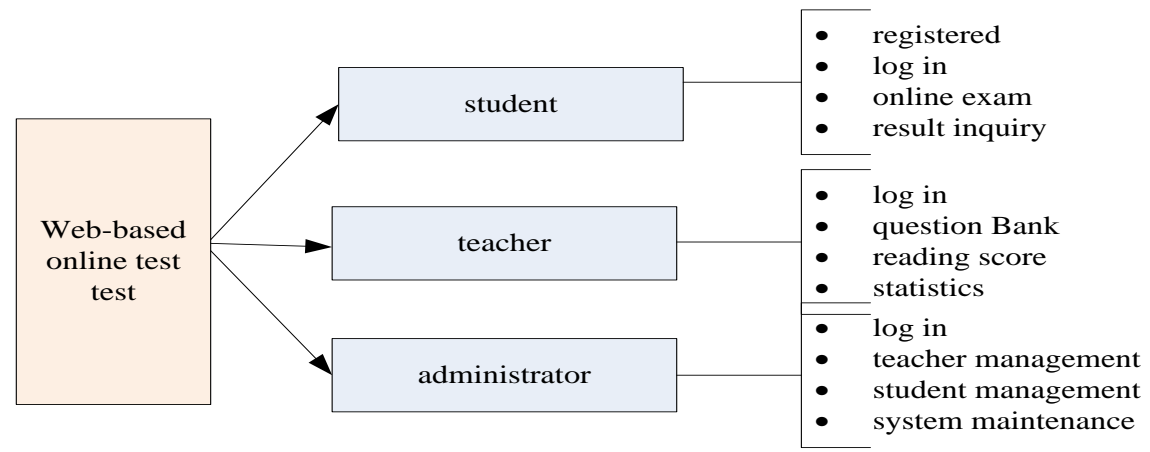

Figure 2. The overall function design of online examination system.

At present, there are two kinds of online examination system structures, namely, client/server mode (C/S Client/Server) (Hung, Huang \& Hwang, 2014; Tang, 2016) and browser/server mode (B/S Brower/Server), i.e. the Web-based mode. The C/S mode consists of two layers: the client-end and the server-end, when implementing the system, the client-end and server-end programs need to be installed separately.

\section{Students}

For students, specific functions include (Liao, 2007):

(1) The basic information of user registration should be online for the freshmen to enter the school, and the login password should be set for the online examination and the result inquiry after the examination. 
(2) After students log into the examination system, they need to finish the objective test first and then prepare to record their voices for the subjective test, which mainly includes sentences in a specific context, dialogues and topic presentation. This will guarantee the authenticity of the whole responding process.

(3) Students can check their test scores and read through the feedback. For example, students can contrast their reading and stress patterns with those of the model and get an auditory and visual feedback so as to better understand their problems.

\section{Teachers}

For teachers, specific functions include (Sung, Hwang, Lin \& Hong, 2017):

(1) Teachers can log in the examination system according to their work number and password. Before the examination, they can input, add, modify and delete the questions in the examination database at any time. They need to specify whether the attributes of the questions are objective or subjective wwhen the questions are input.

(2) After the examination, the teacher can log in the system and count the items such as the highest score, the lowest score, the average score, the total score and the percentage of the number of students in each exam by class. The results of the score statistics are given by the system to help teachers analyze the teaching effect and the difficulty of the test paper and reduce the workload of teachers. After the teacher analyzes the statistics, he / she can sort out students' problems in phonemes, stress, rhythm and intonation and give suggestions for further study. Meanwhile, the teacher can also add some specific exercises or patterns for students to practice, according to their performance in the online test.

\section{The administrator}

For administrators, specific functions include:

(1) The system administrator has the authority to manage students' admission number, password, name, mailbox, department, grade and class information. Administrators can realize the functions such as adding, deleting, modifying, disabling, enabling and querying of student users, such as setting students' permission, allowing students to modify the login password, not allowing illegal users to do any operation on the system data, and not allowing student deleting or modifying the test database.

(2) The system administrator uses the system's teacher staff number, password, name, mailbox, department, teaching subject and other information for management. The administrator can realize the functions of adding, deleting, modifying, disabling, enabling and marking exam papers of the teacher users, and set up a series of authorities for teachers to input test questions, maintain test database, and analyze scores.

(3) The system administrator can also backup and maintain the examination. The administrator is responsible for the whole process from the beginning of the examination to the end of the examination, including 
the student login, online practice and examination, examination timing, examination paper preservation and accident handling and other management functions.

\section{System architecture}

During the exam, the client-end is responsible for the interaction of examinees. The examinees' exam request information will be transmitted to the server through the network, and the server-end is responsible for the generation of the exam papers, and the generated exam papers are transmitted from the server to the examinees' client-end. For the daily management of the B/S mode application system, it only needs to manage the server-ends, which highlights the simplicity of the operation and maintenance of the client-end users, while the server-end only needs to improve the server performance and system operating efficiency, and satisfy the user's needs for system performance and functionality. This system adopts the B/S mode. The specific system structure is shown in Figure 3.

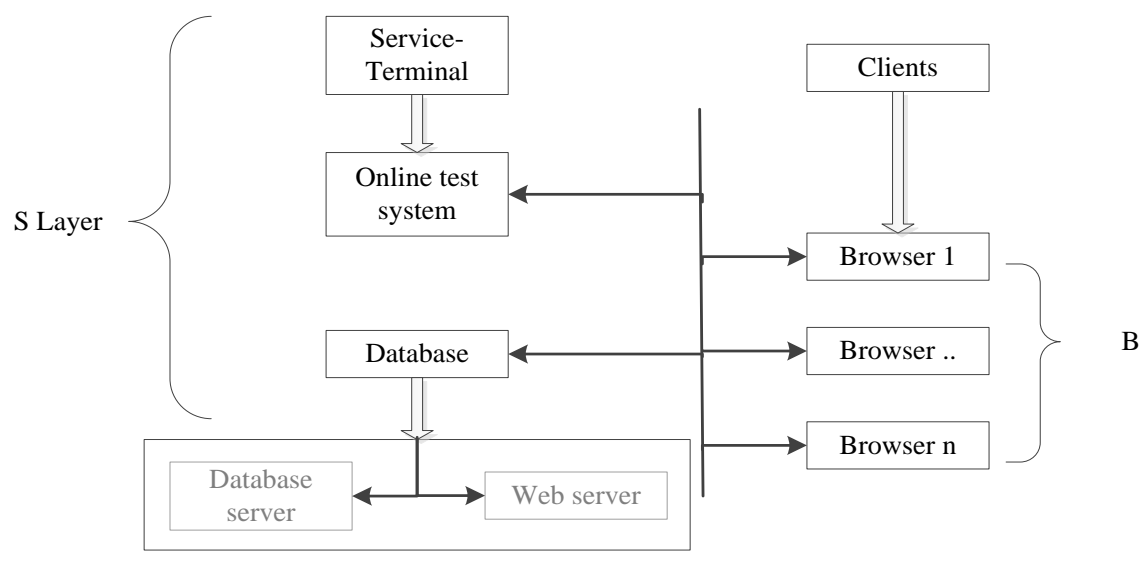

Figure 3. Web-based online examination system architecture.

\section{The main function module design}

\section{Key technologies}

This system uses ASP.NET, which is a part of the Microsoft .NET system. It is a program architecture built on a common language and a general-purpose Web development model. ASP.NET can be written in multiple languages and by using it we can build powerful Web applications, ASP.NET's built-in Windows authentication and configuration based on each application have all ensured the security of the application, so the function and practicality of the whole ASP.NET platform is more suitable for the development of Web applications, it's also suitable for the Web-based online examination system development. 


\section{Design of major functional modules}

According to the demand analysis, besides storing the information of students, teachers, and administrators, the 3 types of users, the database of the online examination system also needs to store various subject exam information and student exam score information and so on. The Web-based online examination system has 4 functional modules: user login, online examination, question bank management and scoring. The core modules are the online examination and rreviewing. Among which:

User login. The system distinguishes the three types of users: students, teachers, and administrators by different coding methods. Different users have different rights to use the system and the operations they can perform are also different. Users need to $\log$ in to the system before using the system. The login page requires to enter the user account and password, once the information is submitted, the system will verify that whether the entered account and password are correct or not, if correct, then the user can log in successfully (Note: for log-in users with different rights, the functional selection interface is also different), otherwise the system displays an error message interface and asks the user to re-enter the account and password. The specific user login flow chart is shown in Figure 4.

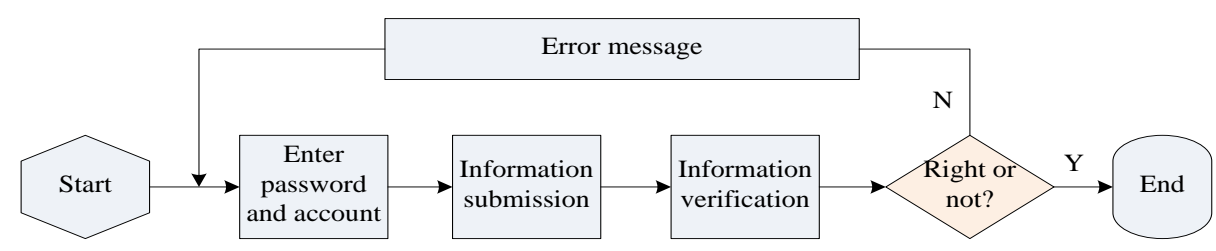

Figure 4. User login process.

Change user login password. The system provides users with the function to change the password. Users need to use the original password to log in to the system before changing the password, then click the Change Password button to enter the Change Password page. After entering the original password, the user can enter the new password and confirm the new password. The system will again verify that the original password entered by the user is correct. If the input is correct, it will verify whether the new passwords entered twice by the user are the same. If they match, the password will be changed successfully, otherwise, an error message will be displayed and the login will be required again. The flow chart of the specific password changing function is shown in Figure 5.

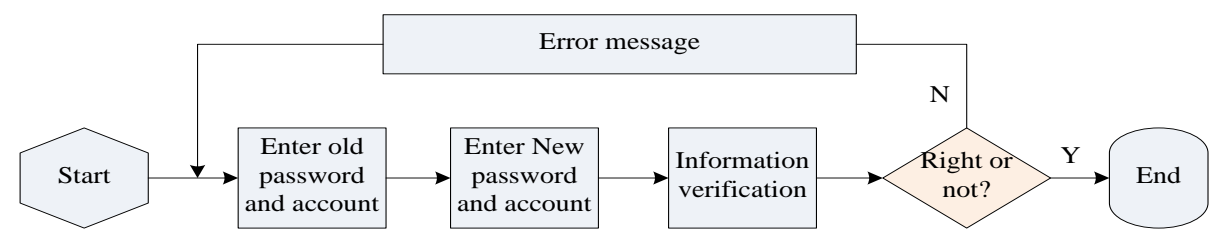

Figure 5. Flow chart for password changing.

Online examination. The online examination is one of the important modules of the system. Once the student logs in successfully and selects the appropriate test subject, at this time the system will first check 
whether the student has an active test, if not, this operation is ignored; if there is, the system will automatically generate exam papers according to the exam information (exam subject, number of questions, difficulty ratio, exam time, etc.). When the examinee starts answering, the system starts timing. During the objective test, the system can save the student's answers immediatelyy. There will be a certain amount of time for students to prepare for the subjective test, but they have only one chance. When the exam time runs out, the system will automatically close the exam paper. After the exam paper is submitted, the objective questions in the exam paper system will be automatically scored, and the scoring result will be saved to the score information table. For the detailed pronunciation and intonation, they will also be saved in the corresponding information table. The system will start the speech recognition software KayPENTAX and PRAAT to conduct an acoustic analysis in terms of suprasegmental elements, such as word stress, sentence stress, juncture and intonation, and then generate scores. At last, the system sums the objective and subjective scores, and sends the results to the score information table; the examinees can log in online to check their scores.

Reviewing module. The test-paper reviewing is done manually by the teachers, according to the statistics. After teachers log into the system, they can select the paper review option and enters the reviewing interface. Teachers can call the examinees' paper to conduct the review by selecting the exam subject and examine the exam papers one by one until all exam papers are reviewed. During the review process, teachers can sort out the problems in English pronunciation and intonation, analyze the possible reasons and put forward some solutions or learning strategies. The specific flow chart for exam paper reviewing is shown in Figure 6.

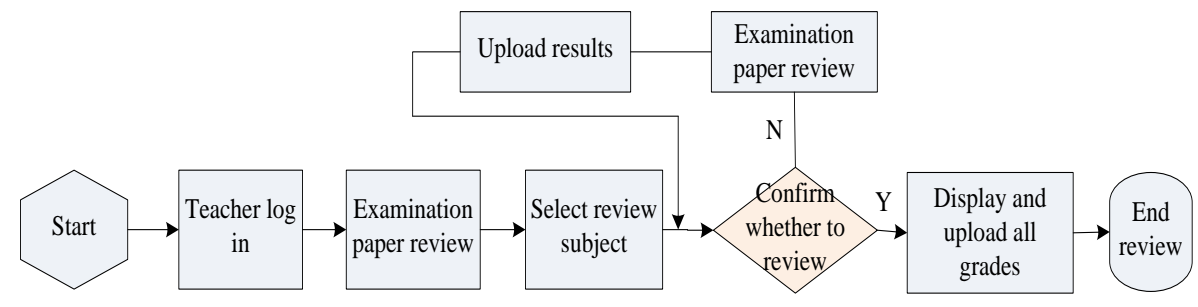

Figure 6. Review the examination process.

\section{Conclusion}

Most of the functions of the Web-based online examination system of English pronunciation designed in this paper satisfy the actual demand of English teachers in the teaching process. For students, the system is userfriendly, simple to use, and students can also answer more quickly, which is more conducive for them to use the learnt knowledge of their own. For teachers, the system provides an automatic scoring module, and both the objective part and the subjective part in the test can be scored automatically, which saves time for teachers to mark and score the papers, reduces their work intensity and overcomes possible errors in the traditional way of reviewing and scoring test papers. At the same time, the system also provides an online review function, which helps teachers understand the status quo in students' learning of English pronunciation and intonation and improve their teaching effect. The system is a paperless system, where students do not need to use papers during 
the examinations, which reduces paper waste. Therefore, the Web-based online examination system of English pronunciation and intonation has good versatility and flexibility, and it has good value in the teaching reform.

\section{References}

Ab Rahman, N. H., Cahyani, N. D. W., \& Choo, K. K. R. (2017). Cloud incident handling and forensic-bydesign: cloud storage as a case study. Concurrency and Computation: Practice and Experience, 29(14). https://dx.doi.org/10.1002/cpe.3868

Freire, C. E. D. A., \& Painho, M. (2014). Development of a mobile mapping solution for spatial data collection using open-source technologies. Procedia Technology, 16, 481-490. http://dx.doi.org/10.1016/j.protcy.2014.10.115

Gaudencio, M., Dantas, A., \& Guerrero, D. S. (2014). Can computers compare student code solutions as well as teachers? ACM Technical Symposium on Computer Science Education, 17(2), 418-423. http://dx.doi.org/10.1145/2538862.2538973

Gupta, S., \& Gupta, B. B. (2018). XSS-secure as a service for the platforms of online social network-based multimedia web applications in cloud. Multimedia Tools and Applications, 77(4), 4829-4861. https://doi.org/10.1007/s11042-016-3735-1

Han, G., Chen, J., He, C., Li, S., Wu, H., Liao, A., \& Peng, S. (2015). A Web-based system for supporting global land cover data production. ISPRS Journal of Photogrammetry and Remote Sensing, 103, 66-80. http://dx.doi.org/10.1016/j.isprsjprs.2014.07.012

Hung, C. M., Huang, I., \& Hwang, G. J. (2014). Effects of digital game-based learning on students' self-efficacy, motivation, anxiety, and achievements in learning mathematics. Journal of Computers in Education, 1(2-3), 151-166. http://dx.doi.org/10.1007/s40692-014-0008-8

Ivanov, A., \& Cyr, D. (2014). Satisfaction with outcome and process from web-based meetings for idea generation and selection: the roles of instrumentality, enjoyment, and interface design. Telematics and Informatics, 31(4), 543-558. http://dx.doi.org/10.1016/j.tele.2013.12.004

James, P. S., Matthew, S., \& Samrachana, A. (2018). Constructing “experts" among peers: educational infrastructure, test data, and teachers' interactions about teaching. Educational Evaluation and Policy Analysis, 40(4), 586-612. https://doi.org/ 10.3102/0162373718785764

Liao, Y. K. C. (2007). Effects of computer-assisted instruction on students' achievement in Taiwan: a metaanalysis. Computers \& Education, 48(2), 216-233. http://dx.doi.org/10.1016/j.compedu.2004.12.005

Lwoga, E. T. (2014). Critical success factors for adoption of web-based learning management systems in Tanzania. International Journal of Education and Development Using Information and Communication Technology, 10(1), 4.

Pimentel, V. \& Nickerson, B. G. (2012). Communicating and displaying real-time data with websocket. IEEE Internet Computing, 7(2), 218-224. http://dx.doi.org/10.1109\%2Fmic.2012.64

Schaffner, E., Schiefele, U., \& Ulferts, H. (2013). Reading amount as a mediator of the effects of intrinsic and extrinsic reading motivation on reading comprehension. Reading Research Quarterly, 48(4), 369-385. http://dx.doi.org/10.1002/rrq.52 
Sung, H. Y., Hwang, G. J., Lin, C. J., \& Hong, T. W. (2017). Experiencing the Analects of Confucius: An experiential game-based learning approach to promoting students' motivation and conception of learning. Computers \& Education, 110, 143-153. https://doi.org/10.1016/j.compedu.2017.03.014

Tang, L. (2016). Exploration on cultivation of critical thinking in college intensive reading course. English Language Teaching, 9(3), 18. http://dx.doi.org/10.5539/elt.v9n3p18

Zacharis, N. Z. (2015). A multivariate approach to predicting student outcomes in web-enabled blended learning courses. The Internet and Higher Education, 27, 44-53. http://dx.doi.org/10.1016/j.iheduc.2015.05.002

Zhang, X. (2017). Field composition and development trend of research hotspots of translation technology in China - based on co-word visualization analysis of relevant academic journals from CNKI published from 1999 to 2017. Theory and Practice in Language Studies, 7(12), 1210-1221. http://dx.doi.org/10.17507/tpls.0712.07 